\title{
Development of Graphic Education in Modern Education
}

\author{
Yu Xifa ${ }^{1}$ Shao Likang ${ }^{2}$ Liu Jipeng ${ }^{3}$ Yu Yan ${ }^{4}$ \\ ${ }^{1}$ Yangzhou University, Yangzhou, Jiangsu Province, China \\ ${ }^{2}$ Army Officer Academy of the Chinese People's Liberation Army, \\ Hefei, Anhui Province, China \\ ${ }^{3}$ Henan Institue of Engineering, Zhengzhou, Henan Province, China \\ ${ }^{4}$ Beijing Foreign Studies University, Beijing, China
}

\begin{abstract}
:
Education comprises every social activity that improves people's knowledge and skills and influences their ideology and morality. Society teaches men knowledge and behaviour codes, with which men can improve society itself. Graphic education studies how to cultivate and exercise graphic thinking, thereby enabling the students' swift understanding and application of graphic technologies. It is the responsibility of all graphic educators to study the connotation, characteristics, latest research results and the trend of graphic education, to work out a development programme that suits China, to achieve a leaping development of graphic education, and to foster talents for the realisation of the Chinese Dream.
\end{abstract}

Keywords: Graphic education; connotation; present situation; latest achievements; trend of development

\section{Introduction}

This essay analyses the connotation, features, latest research results, and trend of graphic education, thereby providing foundational data as well as suggestions for the authorities to work out a development programme of graphic education.

In Chinese, the word 'book' comprises two calligraphies - 'picture' and 'writing'. Zheng Qiao, a Song Dynasty historian, writes in his Tong Zhi, or Consummate Records: 'Ancient scholars follow this rule when they study: they learn shapes from pictures, which they put on the left side, and they seek reasons from writings, which they put on the right side ${ }^{,[1]}$. Also, 'no one can accomplish a great undertaking without the help of pictures and graphs $^{,[2]}$. Lî Kî̀, or The Book of Rites, says: '.. the ancient kings, when establishing states and governing the people, made instruction and schools a primary object $^{[3]}$. Given the historical significance of graphics, it is easy to deduce the indispensability of graphic education.

Examples abound to illustrate the importance of graphics. Ying Zao Fa Shi, or Architectural Methods, written by Li Jie of Song Dynasty, is a comprehensive masterpiece of traditional Chinese architecture. As a guide to engineering construction, this book devotes half of its content to architectural drawings and figures. Tian Gong Kai Wu, or The Exploration of the Works of Nature, written by Song Yingxing of Ming Dynasty, is the first comprehensive work of agriculture and handicraft production in the world, and it consists mainly of illustrations. An even more pervasive example is Qing Ming Shang $\mathrm{He} \mathrm{Tu}$, or Along the River during the Qing Ming Festival, a handscroll painting drawn by Zhang Zeduan of Song Dynasty. Without taking recourse to any words, this painting vividly portrays the townspeople's life and the urban scenery of the capital city, Bian Liang. As the folk adage goes: 'A picture is worth a thousand words'. 
In modern times, alongside the development of industrial and agricultural production, architectural science and information technology, graphics has enjoyed rapid growth. It has formed its own theoretical system: engineering graphic is the major medium for the definition, expression and transportation of project and product information during the process of conception, design, and manufacture; as the 'language of engineering', it is widely used in areas like mechanics, civil engineering, architecture, hydraulics, horticulture, navigation, and astronautics; moreover, modern graphic technology has extended its application from the traditional artistic arena to the task of image procession and information transmission in modern branches such as digital technology, media, and telecommunication. Correspondingly, graphic education has also formed its own characteristics.

The growth of computer and digital technology has helped modern graphics to take a leap in quality improvement, as can be seen in the widespread application of the following techniques: computer graphics, visualisation of scientific computation, realistic image rendering, virtual reality system, geographic information system, image fusion, advanced modelling and simulation technique, computer system of art and animation production, and 3D printing. We may predict that, given the incessant improvement and innovation of technologies, modern graphic technologies will be ever perfected and widely applied to various branches, ranging from scientific research, navigation and astronautics to project planning, artistic design, production practice and simulated training; that it will become a useful tool for mankind to explore nature and to fumble the future; that graphic education will definitively flourish.

\section{Connotation of Graphic Education}

\subsection{Education and Graphic Education}

Education comprises every social activity that improves people's knowledge and skills and influences their ideology and morality. Society teaches men knowledge and behaviour codes, with which men can improve society itself. Graphic education studies how to cultivate and exercise graphic thinking, thereby enabling the students' swift understanding and application of graphic techniques.

Modern graphics covers every domain related with graphs (figures and images), and it can be classified into artistic graphics (dealing with art) and applied graphics (including engineering graphics and computer graphics/iconology).

\subsection{Artistic Graphic Education (Art)}

Artistic graphic education comprises four stages: pre-school education, compulsory education, secondary education, and higher education. It consists of drawing, colours, pattern design and basic computer graphics; none of these shall be discussed in the present essay.

\subsection{Applied Graphic Education}

Applied graphics includes engineering graphics and iconology.

1) Engineering Graphics

Engineering graphics studies how to express, communicate and transmit information of engineering projects and products. Engineering graphic is the carrier of project and product information; it is the language through which engineers communicate and express themselves ${ }^{[4]}$.

2) Iconology

Iconology can be further divided into traditional iconology and modern iconology. The former mainly studies the art of painting, focusing on the essential substance of an art work hidden behind its form, image, theme, and plot. It can also 
be applied to the field of architecture, where it studies the interrelation of a building's form, structure, function and symbolic meaning. In this case, it is called Architectural Iconology ${ }^{[5]}$.

In the wake of the development of computer technology and digital technology, modern iconology has extended its range of research subjects, which now include formation, display and transmission of images, image procession, and image recognition. Due to its colourfulness and vividness, image has infiltrated into every aspect of human living, becoming an important component of modern media and communications as well as information technology. Modern graphic technology has also been applied to radar tracking, satellite positioning, lunar landing project and Mars exploration. In these cases, the importance of graphics cannot be replaced by any other media, for instance words.

\subsection{Difference between Graphic Educa- tion and Education of Other Disci- plines}

Every discipline has its own features. Due to their different contents, disciplines differ in teaching methods and goals. If we compare graphic education with liberal arts or mathematics, we can see that they differ in ways of thinking and cultivation of capacities.

Human beings have various ways of thinking; for instance, terms like abstract thinking, concrete thinking, logical thinking and divergent thinking are familiar to us all. Nowadays has appeared a new concept called 'innovative thinking'. In the field of graphics, we also hear of terms like 'imagery thinking' and 'graphic thinking'.

Education of liberal arts focuses on the cultivation of abstract thinking, so that people can excel in speech and persuasion; education of mathematics emphasises logical thinking, and aims at equip- ping men with the capability to analyse, deduce, and calculate.

What graphic education pays most attention to is imagery thinking. It demands an active mind of men, with which men should excel in both spatial imagination and imagery expression. This combination of mental and manual labour is also beneficial for the development of the right brain, which is now regarded as a boot to success in modern society.

Albert Einstein once remarked that he contemplates problems not in words, but in active images. 'Imagination is more important than knowledge', so goes his famous quote. Imagination imps the wings of innovation; spatial imagination assists us to improve the world and create a better one. Figure 1 shows the functions of graphic education.

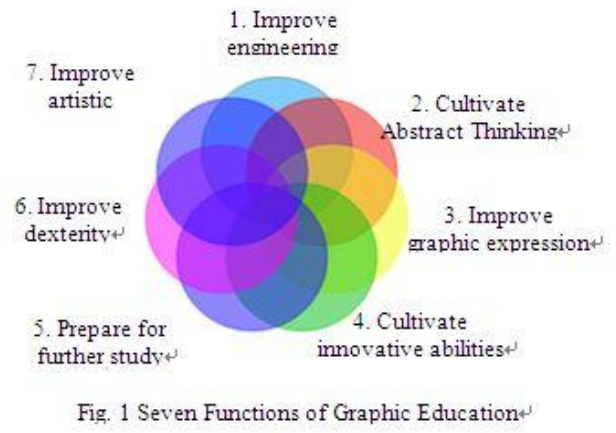

\section{Chinese Graphic Education: Its Pre- sent Situation and Latest Achieve- ments}

\subsection{Present Situation of Chinese Graphic Education}

The present essay does not concern itself with the absence of artistic graphic education; instead, it deals with the discipline of applied graphics, where traditional technical drawing and modern computer graphics interact and intermingle. Consequently, the

ing graphics serves as the foundational technical course, which holds two func 
curriculum of graphics in colleges and universities could also be divided into two aspects: technical drawing and computer graphics.

3.1.1 Traditional Curriculum of Engineering Graphics

In the curriculum of engineering in mainland China, engineer it tions: firstly, cultivates and exercises spatial thinking, structural imagination and design ability through theoretical lessons of projection drawing; secondly, it equips students with rudimentary knowledge of engineering through introduction and practice of technical drawing under the national standards. It has two different systems of pedagogy: the traditional one focuses on the training of spatial geometric thinking and emphasises systematic theories; the more recent pedagogy stresses the teaching of the language used in engineering design and highlights practicality, and is therefore more adaptable to the current social demands in practice. A typical representative of the second pedagogy is project teaching, which has not yet been widely adopted ${ }^{[6]}$.

Given the disparity between research and practice in the domestic development of technologies, both pedagogies are necessary for graphic education.

3.1.2 Personnel Training Centring on the Requirement of Computer Graphic/Imagery Technology

The rapid development of computer graphic/imagery technology has enriched the contents of corresponding courses and raised the required standards for related technical talents. This phenomenon can be observed in various professions, ranging from traditional industries like engineering design and advertisement to modern trades like animation design, office automation and advanced information procession. The great value set on computer graphic/imagery technology promises a bright future of its related personnel training.
3.1.3 Application of Multimedia in Teaching Methods

In pace with the development of office software and CAD software, technologies like animation, video and virtual reality have been widely applied in teaching and have helped to enhance the vividness in graphic education. Despite these advantages, reliance on software and virtual symbols has weakened students' ability to think in terms of images, and this problem is particularly grave in domestic engineering education.

\subsection{Latest Achievements of Graphic Education}

Teachers of graphic education have been exploring how to reform their subject, and they have harvested abundant fruits, which can be summarised as follows:

3.2.1 Research on the Patterns of Graphic Education Reform

1) Improvement on the integration pattern of serial courses

2) Development of the chunk coordination pattern, in which appears some new graphic courses

3) Deepening of the infrastructurebased comprehensive promotion pattern

4) Deepening of the 3D-centred pattern

3.2.2 Construction of Teaching Materials

1) In the field of traditional graphic education, there are seven textbooks which are enlisted under the project of Thousand Excellent Course Materials of Higher Education, for instance Electronic Teaching Plans and Solution Guides to Descriptive Geometry, published by Dalian University of Technology.

2) Materials on computer graphic/imagery technology have sprung up in recent years, producing excellent yet diverse results.

\subsubsection{Excellent Courses}

In accordance with the Construction of Excellent Courses initiated by the Ministry of Education, numerous excellent 
courses of graphic education at national or provincial level have appeared, including: Applied Computer Graphics (led by

Tan Jianrong of Zhejiang University), Engineering Graphics (led by Lu Guodong of Zhejiang University), Mechanical Graphic Design and Basic CAD (led by Shi Yueding of Zhejiang University), Graphic Design (led by Xun

Shenglan of Jiangnan University), Digital Graphic Procession (led by Xu Luping of Xidian University). In particular, the course of Engineering Graphics led by professors Lu Guodong and Shi Yueding have become one of the first five courses approved by the National Centre of Elearning under the Ministry of Education.

Chinese graphic teachers have made much endeavour and exploration in the construction of excellent courses, and they have contributed a lot to the course construction and quality improvement of the graphic discipline. Currently, out of the 2582 national excellent undergraduate courses, 69 cover the field of graphics; out of the 5648 provincial excellent undergraduate courses, 69 are graphicrelated. For higher education institutions of vocational and professional training, 28 out of 1041 national excellent courses deal with graphics; and 88 out of 2636 provincial excellent courses teach graphics.

\subsubsection{Teaching Groups}

Three teaching groups, for instance that of engineering graphics led by professor Lu Guodong of Zhejiang University, have been appraised as national teaching group ${ }^{[7]}$.

3.2.5 Awards for Teaching Achievements

Achievements of Graphic Education have received many awards of collegiate, provincial, or national levels. Five projects, for example that of 'Research, Development, and Application of Teaching Resources of Engineering Graphics' led by academician Tan Jianrong of Chinese Academy of Engineering, have attained the 'The Sixth National Teaching Achievements Award of Higher Education' ${ }^{[8]}$.

\section{Trend of the Development of Graph- ic Education}

\subsection{Graphic Education as Lifelong Ed- ucation}

The rapid development of computer technology and graphic technology makes school education no longer sufficient for lifelong occupation. Therefore, lifelong education necessarily becomes the pattern for us to learn the latest graphic technology.

\subsection{Reform of Teaching Methods- Students as the Core and Teacher as the Guide}

Given the rapid development of the science and technology and the ever intense economic competition, graphic education of the 21 st century should orient itself toward the cultivation of students' capabilities and qualities, particularly their ability to think, analyse and solve problems. In short, the educational ideology should transform its essence from 'impartation of knowledge' to 'cultivation of abilities'.

\subsection{Reform of Teaching Methods- Further Application of Multimedia, Intelligence, and Internet}

1) Multimedia

Computer multimedia technology has numerous advantages: it can simultaneously stimulate multiple senses and transmit huge amounts of information both fast and good; it can be applied to various walks of life; and it allows handy operation and excellent interaction. Predictably, this technology shall be irresistible to the field of graphic education.

2) Intelligence

Development and application of hardware and software systems has aided 
graphic procession to become automatic and intelligent. These computer technologies include: recognition software of handwriting and speech in Chinese and English, CASSCAN software for procession of old drawings, expertise educational system.

3) Internet

Internet quickens the process of knowledge transmission and widens the scope of knowledge obtainment; as a result, e-learning has become an important method of modern education.

In addition, technologies of virtual reality and visualisation have gained ever wider application in modern education, the most successful example being the establishment of virtual laboratory and simulated training system. The interactivity and verisimilitude of virtual reality allows students to take all kinds of technical training in a virtual learning environment, and it proves particularly advantageous for simulation of military and sporting activities. Nowadays the technology of virtual reality has been extended to the fields of engineering manufacture, medical teaching, driving and maintenance of electrical wares .

\section{Conclusion}

In order to work out a development programme of graphic education that is adaptable to the ever changing scientific development and suitable for the current domestic condition, the authors propose the following suggestions, which they believe will help facilitate a great-leapforward development of graphic education and cultivate talents for the realisation of the Chinese Dream:

1) Early Start of Graphic Education

2) Strengthening of General Education

3) Vigorous Promotion of the Construction of Teaching Materials

4) Strengthening Faculty Development

\section{Acknowledgement}

This essay has been included in the Report of the Development of the Graphic Discipline (2012-2013) of China Association for Science and Technology as a phase achievement.

\section{References:}

[1] Zheng Qiao. Tong Zhi: Er Shi Lue. Shanghai: Zhonghua Book Company, 1995. 1825

[2] Zheng Qiao. Tong Zhi: Er Shi Lue. Shanghai: Zhonghua Book Company, 1995. 1827

[3] Legge, James, tr. The Lî Kî or The Book of Rites. Oxford: OUP, 1885. Vol. 27 of The Sacred Books of the East. Ed. Max Müller. 50 vols. 1879-1910.

$<$ http://www.sacredtexts.com/cfu/liki2/liki216.htm>

[4] China. Ministry of Education. Teaching Guidance Committee for Engineering Graphics. Basic Requirements for the Course of Engineering Graphics in Ord inary Colleges and Universities. 2004. [5] Wu Cong. Outside Projection: A Study of Architectural Graphics from the Perspective of Culture. Tianjin: Tianjin UP, 2004. 92-94.

[6] Tong Bingshu, and Gao Shufeng. 'Some Thoughts on the Cultivation of Students' Innovative Ability in Engineering Graphic Education'. Journal of Engineering Graphics 29.6 (2008):1-6.

[7] Engineering Graphics. Spec. issue of Newsletter of Higher Education Press. 24 July 2009.

[8] Engineering Graphics. Spec. issue of Newsletter of Higher Education Press. 1 August 2012. 